\title{
Shoot Borer Earias Vittella-A Threat to the Indigenous Vegetable Pele Abelmoschus Manihot in the Pacific ${ }^{\dagger}$
}

\author{
Samuel Hone ${ }^{1}$ and Rashmi Kant $2, *$ \\ 1 Department of Biosecurity, Ministry of Agriculture and Livestock, Honiara 1925, Solomon Islands; \\ SHone@biosecurity.gov.sb \\ 2 The New Zealand Institute for Plant and Food Research, Havelock North 4130, New Zealand \\ * Correspondence: rashmi.kant@plantandfood.co.nz \\ + Presented at the third International Tropical Agriculture Conference (TROPAG 2019), Brisbane, Australia, \\ 11-13 November 2019.
}

Published: 13 February 2020

\begin{abstract}
The indigenous vegetable Abelmoschus manihot (Malvaceae) is one of the staple crops in the Pacific island countries. It is known by various local names, including Pele (Samoa, Tonga), Bele (Fiji), Aibika (Papua New Guinea), and slippery cabbage (Solomon Islands). The Food and Agriculture Organisation (FAO) has recommended this as one of the top crops for nutritional security. The leaves of $A$. manihot are consumed raw, in soups and in various local cuisine. Herbivory is a major problem in growing A. manihot; however, farmers are reluctant to use pesticides. We examined the damage caused by the shoot borer Earias vittella (Lepidoptera: Noctuidae) to three common A. manihot varieties, Green (GN), Red Broad (RB) and Red lobed (RL) in Samoa. In both field and laboratory assessments, E. vittella attacked all the selected varieties. Female lay eggs on shoot tips, and the hatched larvae bore into young shoots. The succulent green variety was found to be more susceptible to the borer attack than red varieties. In field assessment, RL was the least attacked by the borers. In the laboratory bioassay, the larvae that developed on RL were much smaller and weaker than those on the other varieties. In sensory testing, the shoot tips of RN were found to have a tougher/fibrous texture that probably made RN undesirable to the borer. Furthermore, the taller plants were found more vulnerable to borer attack. The study suggests that pruning A. manihot could minimise borer attack; and that $\mathrm{RN}$ is a potential variety for future breeding programmes.
\end{abstract}

Keywords: slippery cabbage; Malvaceae family; staple crop; Lepidoptera; Noctuidae

Funding: This research received no external funding.

Acknowledgments: We would like to acknowledge staff and students of USP for their help in collecting data.

Conflicts of Interest: The author declares no conflict of interest.

(C) 2020 by the authors. Licensee MDPI, Basel, Switzerland. This article is an open access article distributed under the terms and conditions of the Creative Commons Attribution (CC BY) license (http://creativecommons.org/licenses/by/4.0/). 